http://jmscr.igmpublication.org/home/ ISSN (e)-2347-176x ISSN (p) 2455-0450 crossref DOI: https://dx.doi.org/10.18535/jmscr/v7i7.88

\title{
Assessment of lipid profile in premenopausal and postmenopausal women with Cardiovascular disease
}

\author{
Author \\ R.S. Diana* \\ Professor, Department of Nutrition, Sri Balaji College of Nursing \\ No 7, CLC Works Road, Chromepet, Chennai- 600 044, India \\ *Corresponding Author \\ R.S. Diana
}

\begin{abstract}
Background: Dyslipidemia is highly prevalent among women. The management of dyslipidemia is a cornerstone in the prevention of both primary and secondary cardiovascular events, such as myocardial infarction, ischemic stroke, and coronary death. All major international guidelines on the treatment of dyslipidemia recommend similar approaches to the management of dyslipidemia in both men and women. Women experience a number of hormonal changes throughout their lifetime, including those changes associated with puberty, menarche, pregnancy, and menopause. Each of these hormonal perturbations can alter serum lipoprotein levels. Hence the aim of this study was to assess the lipid profile in pre and post menopausal women.

Materials \& Methods: In this hospital based study100 female patients between the age group of 26-70 were included.

The lipid profile was assessed using standard methodologies. Statistical analysis were performed using the SPSS (Version 16; SPSS Inc., Chicago, IL, USA). Quantitative data were expressed as mean \pm SD.

Results: In our study population 45\% belonged to Grade I obesity, while 19\% Grade II obesity and the remaining $36 \%$ were found to be non-obese. A statistically significant difference was observed in Triglyceride and HDL cholesterol levels ( $p<0.05$ ).

Conclusion: Therefore, it can be concluded that menopause leads to changes in lipid profile by causing significant alterations in total and LDL cholesterol and by reducing HDL cholesterol. The elevated LDL and the reduction of cardio protective HDL is an indication that menopause is an independent risk factor for developing cardiovascular disease.

Keywords: Cardiovascular disease, Cholesterol, Postmenopausal women.
\end{abstract}

\section{Introduction}

The term dyslipidemia is used to denote the presence of any of the following abnormalities, occurring alone or in combination-increased concentration of TC or LDL-C or serum TG or a decreased concentration of HDL-C.

Numerous studies conducted in Indians have revealed that various forms of dyslipidemia such as high total and low-density lipoprotein cholesterol (TC and LDL-C), low high-density lipoprotein cholesterol (HDL-C) and high triglycerides (TG) are highly prevalent. At the same time, while extensive guidelines are available for management of dyslipidemia in US and Europe, no specific guidelines exist for lipid management among Indians. 
Several epidemiologic studies have shown that postmenopausal women tend to have significantly different lipid profiles as compared with premenopausal women.( Bonithon-Kopp C 1990, $\mathrm{Wu} \mathrm{Z}$, 1990) A number of lipoprotein changes occur that characterize the menopausal transition. (Akahoshi M, 1996) Post-menopausal women have increased levels of LDL-C, total cholesterol, and apolipoprotein $\mathrm{B}$ as compared with premenopausal women. In the Framingham Study, investigators documented an increase in cholesterol levels that coincided with menopause, suggesting a causal role of menopause in altering lipid levels. (Hjortland MC 1976) In addition to a higher LDL-C, investigators have noted menopause to be associated with a transition in LDL particles to more atherogenic smaller and more dense particles. (Carr MC,2000) Total HDL cholesterol and HDL2 also decrease in postmenopausal women. (Matthews KA, 1989) Elevated Lp(a) levels has been associated with an increased CHD risk and has been reported to increase in women following total hysterectomy and oophorectomy.( Lip GY, 1997) There are many correctable risk factors for ASCVD. Of these, dyslipidemia has the highest population attributable risk for myocardial infarction (MI), Yusuf S, 2004) 1 both because of its high prevalence and also because of its direct pathogenic association with atherosclerosis. Accordingly, effective management of dyslipidemia remains one of the most important healthcare targets for prevention of ASCVD.

\section{Purpose}

The purpose of this study is to investigate the lipid profile and prevalence of dyslipidemia, as serum lipid levels have a major contribution in the development of cardiovascular diseases, in adult women of South Indian population

\section{Materials \& Methods}

In this hospital based study.100 female patients between the age group of 26-70 were included.

The individuals exhibited no co morbidities other than dyslipidemia. The anthropometric data were recorded. The lipid profile was done using standard methodologies. Dyslipidemia was assessed based on the criteria given in the Third Report of the National Cholesterol Education Program Expert Panel on Detection, Evaluation and Treatment of High Blood Cholesterol in Adults (NCEP ATP-III).

\section{Results}

Fig 1.0 Representing the distribution of obesity in the study population

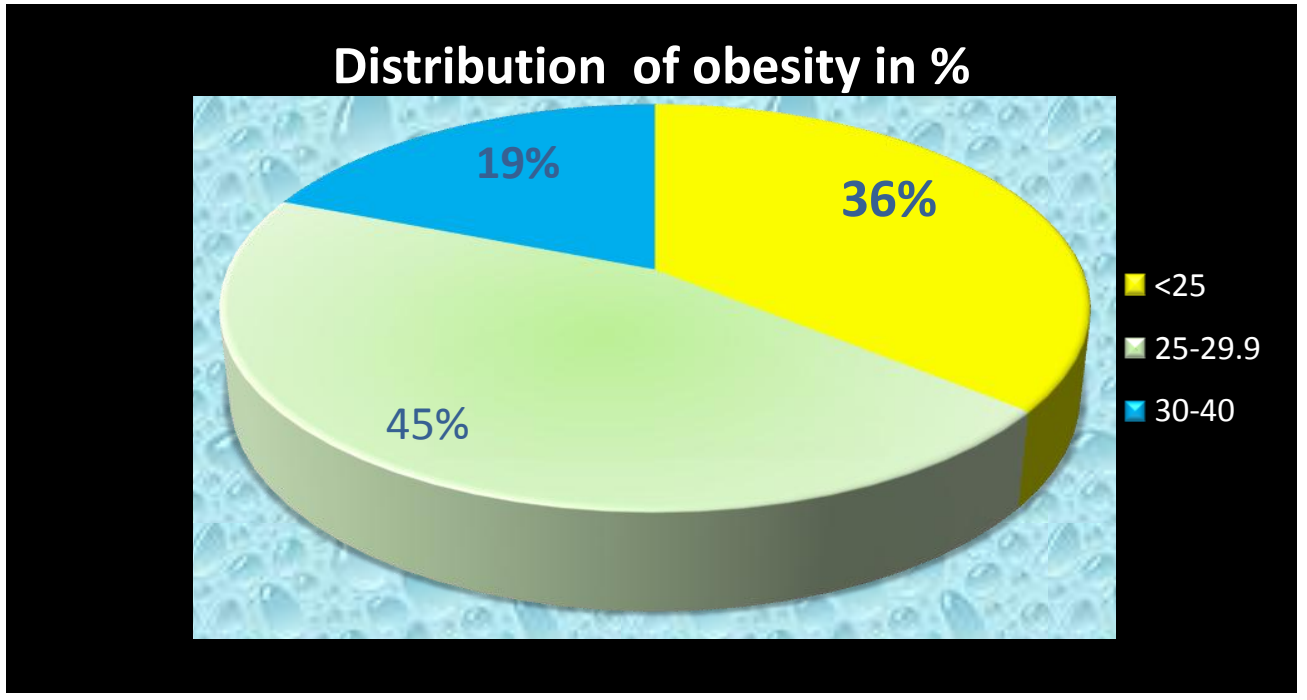

The above figure represents the distribution of obesity among our study population. $45 \%$ of them belonged to Grade I obesity, while $19 \%$ belonged to Grade II obesity and the remaining $36 \%$ were found to be non-obese. 


\section{JMSCR Vol||07||Issue ||07||Page 486-492||July}

Table 1.0 Level of lipid parameters in pre-menopausal and post menopausal women

\begin{tabular}{|l|c|c|cc|c|}
\hline S.No & Parameters & $\begin{array}{c}\text { Pre-menopausal } \\
\text { Women }(\mathrm{n}=50)\end{array}$ & $\begin{array}{c}\text { Post-menopausal } \\
\text { Women }(\mathrm{n}=50)\end{array}$ & P value \\
\hline 1. & Total cholesterol $(\mathrm{mg} / \mathrm{dL})$ & $160 \pm 35$ & $171.6 \pm 121$ & 0.518 \\
\hline 2. & Triglyceride $(\mathrm{mg} / \mathrm{dL})$ & $139 \pm 56$ & $166 \pm 76$ & $0.044^{*}$ \\
\hline 3. & HDLc $(\mathrm{mg} / \mathrm{dL})$ & $36.6 \pm 7$ & $41.6 \pm 15$ & $0.035 *$ \\
\hline 4. & LDL $(\mathrm{mg} / \mathrm{dL})$ & $95 \pm 35$ & $96.8 \pm 35$ & 0.790 \\
\hline *P value $<0.05$ is considered statistically significant.
\end{tabular}

From the above table it can be inferred that, the mean levels of the lipid parameters are higher in Post-menopausal women when compared to the pre-menopausal women, indicating that postmenopausal women are at a greater risk of developing CVD in the future.
A statistically significant difference was observed in Triglyceride and HDL cholesterol levels ( $p$ $<0.05)$

Fig 2.0 Represents range of triglyceride levels of the study group in \%

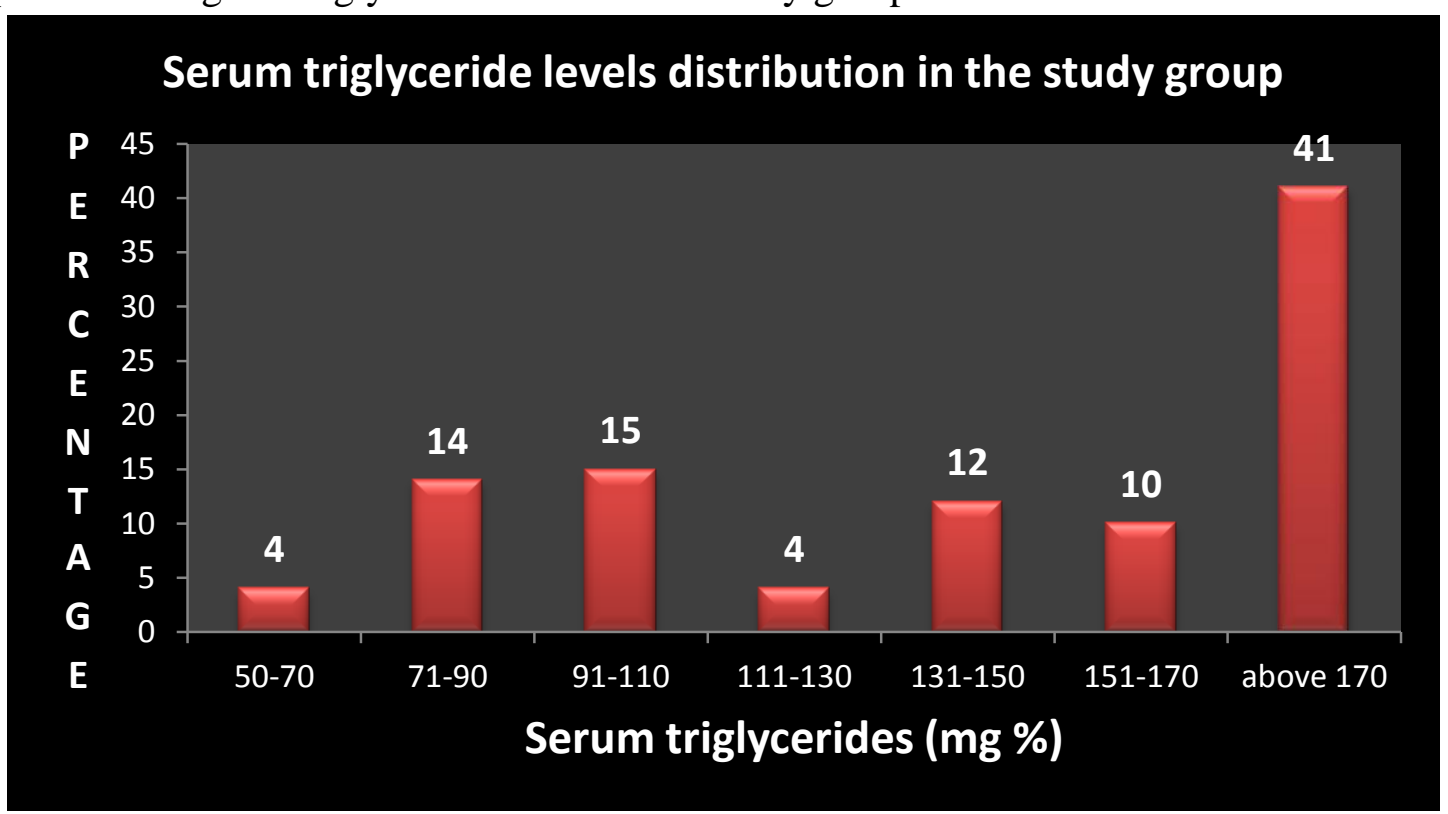

Fig 3.0 Represents HDL cholesterol levels of the study group in \%

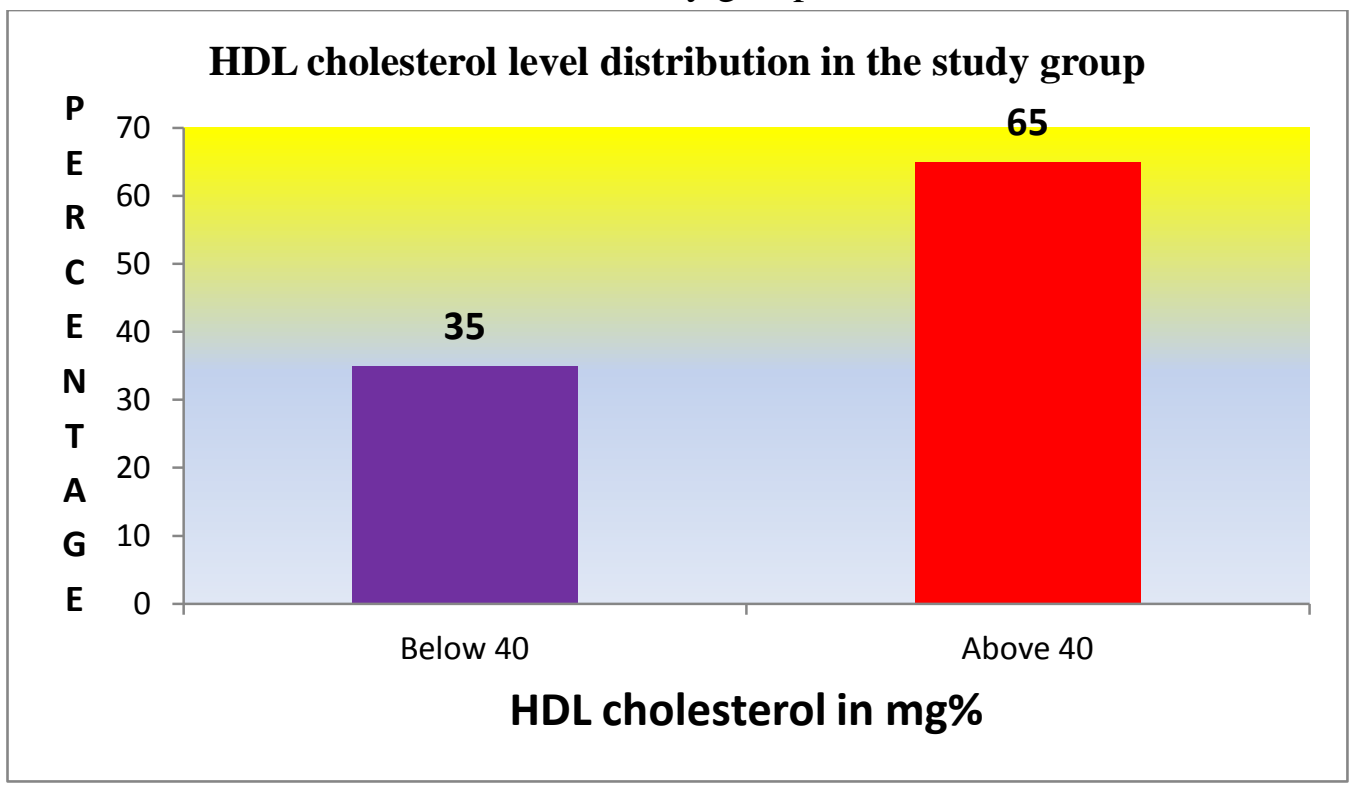




\section{Discussion}

The present study was undertaken to evaluate the levels of serum lipid profile in pre- and postmenopausal women.

The incidence of CHD in women is significantly lower before menopause, a protection that has been attributed to the effects of estrogen.

Natural menopause confers a 3-fold increase in CHD risk (Kannel WBWilson 1995) In the Nurses' Health Study cohort, women undergoing bilateral oophorectomy had up to an 8-fold increase in risk of CHD. (Colditz 1987) After age 50 years, cholesterol levels plateau in men; however, levels of low-density lipoprotein (LDL) cholesterol increase an average of $0.05 \mathrm{mmol} / \mathrm{L} \mathrm{(2}$ $\mathrm{mg} / \mathrm{dL}$ ) per year between ages 40 and 60 years in women(Johnson 1993) At least part of this increase results from declining levels of estrogen, which result in down-regulation of the LDL receptor on the liver. (Welty FK 2001) A high LDL cholesterol level is a strong predictor of CHD risk in women younger than 65 years and a somewhat weaker predictor in women aged 65 years and older. Increases in levels of total cholesterol, very-low-density lipoprotein (VLDL) cholesterol, and triglycerides have also been observed after menopause. (Campos 1988)

In the cross-sectional National Health and Nutrition Examination Surveys (NHANES), highdensity lipoprotein (HDL) cholesterol levels were lower in men than in women and did not change with age.( Johnson 1993) However, in 2 smaller longitudinal studies, levels of HDL cholesterol decreased in postmenopausal women.( Matthews 1989)A low HDL cholesterol level is a stronger predictor of CHD mortality in women than in men and particularly so in women 65 years of age and older (Mosca 1997, Manolio 1992, Walsh 1995) Stevenson et al,1993 reported that the $\mathrm{HDL}_{2}$ cholesterol subfraction, which is considered to be more cardioprotective than $\mathrm{HDL}_{1}$ or $\mathrm{HDL}_{3}$, showed a marked drop after the onset of menopause. The risk of coronary events increases with each increment in the ratio of total to HDL cholesterol.
The findings in our study are in accordance with other studies done by Kalavathi et al., Muzzio et $a l$., and Matthews et al., where the TC is seen to increase in post-menopausal women due to estrogen deficiency when compared to premenopausal women (Kalavathi L 1991, Matthews KA 1989, Muzzio ML, 2007)

In our study, post-menopausal women had high levels of LDL when compared to pre-menopausal women although not statistically significant. In contrast to other findings reported in various studies.( Kalavathi L, 1991, Swapnali RK, 2011, . Kwiterovich PO 1992) Lipoprotein lipase (LPL) is regulated by circulating estrogen. LPL catalyzes the hydrolysis of VLDL to form intermediatedensity lipoprotein and later LDL. Estrogen deficiency after menopause increases the plasma LPL and hepatic TG lipase activity causing plasma LDL to accumulate and also leads to down-regulation of LDL receptors. (Muzzio ML, 2007, Swapnali RK ,2011, Wakatsuki A, 1995)

The incidence of cardiovascular disease after menopause may be partly caused by changes in the plasma lipid levels that occur following the menopausal transition. (Matthews KA, 1989,. Stevenson JC, 1993, Kuller LH 1994) Deposition of fatty plaques on arterial walls (arteriosclerosis) is a predisposing factor for coronary heart disease.( Kannel WB.1987).

The increased risk of CAD following menopause is mainly related to the endocrine influences on lipid profile especially when other risk factors such as blood pressure, blood sugar, and body weight are normal. Estrogens have a major beneficial effect on cholesterol metabolism and appear substantially to reduce the risk of atherosclerosis and cardiovascular disease in postmenopausal women. (Swarnalatha PK 2012)

Menopause is the permanent amenorrhea, which lasts at least for a period of 1-year due to the cessation of ovarian function. (Padubidri VG, 2004) This results in changes in metabolism of glucose and insulin, body fat distribution, coagulation, fibrinolysis, and vascular endothelial dysfunction. (Spencer CP 1997) It has been 
proposed that estrogen exerts cardioprotective action among pre-menopausal women by maintaining high level of high-density lipoprotein cholesterol (HDL-C) and lowering the low-density lipoprotein cholesterol (LDL-C), and triglycerides (TG). (Adashi EY 1994, Barrett-Connor E, 1991, Groedstein F, 1996,. Wild RA, 1995) Lack of estrogen is an essential contributory factor in the derangement of lipid metabolism in postmenopausal women which is associated with increased cardiovascular risk. (Kalavathi L, 1991) Currently, post-menopausal women account for more than $30 \%$ of the female population at risk for CAD in India. (Arora S,2006)

In our study, when compared to pre-menopausal women, post-menopausal women were having high TG and were statistically significant $(P<$ $0.05)$. These findings are in accordance with other studies done by (Welty and Hallberg and Svanborg, 2001). In the post-menopausal women, there is increased fat accumulation and increased release of free fatty acids into the circulation, and excessive free fatty acids provide substrate for hepatic TG synthesis.( Tankó LB, 2005)

\section{Conclusion}

Menopause leads to changes in lipid profile by elevating TC, TGs, LDL-C, and VLDL-C, thus increasing the risk for cardiovascular disease. Due to the change in the lipid pattern and loss of cardioprotective effect of estrogen, postmenopausal women are at increased risk of developing cardiovascular disease. Various studies reveal the beneficial effects of hormone replacement therapy on the lipid profile in postmenopausal women. Furthermore, few studies disagree on the beneficial effects of hormone replacement therapy in patients with cardiovascular disease. (Abbott RD, 1988, Stampfer MJ, 1991, Cheng GS., 2000) Predicting the factors affecting the lipid profile in postmenopausal women, adopting strategies to control these mechanisms by modifying the relative risk factors during menopausal transition may improve the cardiovascular risk profile in these women.

\section{References}

1. Bonithon-Kopp C, Scarabin P-Y, Darne B, Malmejac A, Guize L. Menopause-related changes in lipoproteins and some other cardiovascular risk factors. Int J Epidemiol. 1990;19(1):42-48. [PubMed]

2. Wu Z, Wu X, Zhang Y. Relationship of menopausal status and sex hormones to serum lipids and blood pressure. Int $\mathbf{J}$ Epidemiol. 1990;19(2):297-302 [PubMed]

3. Akahoshi M, Soda M, Nakashima E, Shimaoka K, Seto S, Yano K. Effects of menopause on trends of serum cholesterol, blood pressure, and body mass index Circulation. 1996;94(1):61-66. [PubMed]

4. Hjortland MC, McNamara PM, Kannel WB. Some atherogenic concomitants of menopause: the Framingham study. Am J Epidemiol. 1976;103(3):304-311.

[PubMed]

5. Carr MC, Kim KH, Zambon A, et al. Changes in LDL density across the menopausal transition. J Investig Med Off Publ Am Fed Clin Res. 2000;48(4):245250. [PubMed]

6. Matthews KA, Meilahn E, Kuller LH, Kelsey SF, Caggiula AW, Wing RR. Menopause and risk factors for coronary heart disease. N Engl J Med. 1989;321 (10):641-646. [PubMed]

7. Lip GY, Blann AD, Jones AF, Beevers DG. Effects of hormone-replacement therapy on hemostatic factors, lipid factors, and endothelial function in women undergoing surgical menopause: implications for prevention of atherosclerosis. Am Heart J. 1997;134 (4):764771. [PubMed]

8. Yusuf S, Hawken S, Ounpuu S, et al. Effect of potentially modifiable risk factors associated with myocardial infarction in 52 countries (the INTERHEART study): Case-control study. Lancet 2004; 364:937-952 
9. Kannel WB Wilson PW Risk factors that attenuate the female coronary disease advantage. Arch Intern Med. 1995;1555761

10. Colditz GA Willett WC Stampfer MJ Rosner BSpeizer FE Hennekens $\mathrm{CH}$ Menopause and the risk of coronary heart disease in women. $N$ Engl $J$ Med. 1987;3161105-1110Crossref

11. Johnson CLR BMSempos CT et al. Declining serum total cholesterol levels among US adults: the National Health and Nutrition Examination Surveys. JAMA. 1993;26930023008Crossref

12. Welty FK. Cardiovascular disease and dyslipidemia in women. Arch Intern Med 2001;161:514-22.

13. Campos HMcNamara JRWilson PWFOr dovas JMSchaefer EJ Differences in low density lipoprotein subfractions and apolipoproteins in premenopausal and postmenopausal women. $J$ Clin Endocrinol Metab.1988;6730- 35Crossref

14. Mosca LManson JE Sutherland SELanger RD Manolio TBarrettConnor E Cardiovascular disease in women: a statement for healthcare professionals from the American Heart Association. Circulation.1997;9624682482Crossref

15. Manolio TA Pearson TAWenger NK Barrett-Connor EPayne GHHarlan WR Cholesterol and heart disease in older persons and women: review of an NHLBI workshop. Ann Epidemiol. 1992;2161176Crossref

16. Walsh JMGrady D Treatment of hyperlipidemia in women. JAMA 1995;2741152- 1158Crossref

17. Stevenson JCCrook DGodsland IF Influe nce of age and menopause on serum lipids and lipoproteins in healthy women Atherosclerosis. 1993;9883-90Crossref
18. Kalavathi L, Dhruvanarayan HR, Zachariah E. Plasma estradiol and lipid profile in perimenopausal women. Indian J Physiol Pharmacol 1991;35:260-2.

19. Muzzio ML, Berg G, Zago V, Basilio F, Sanguinetti S, Lopez G, et al.Circulating small dense LDL, endothelial injuring factors and fibronectin in healthy postmenopausal women. Clin Chim Acta 2007;381:157-63.

20. Swapnali RK, Kisan R, Jayaprakash Murthy DS. Effect of menopause on lipid profile and apolipoproteins. Al-Ameen $\mathbf{J}$ Med Sci 2011;4:221-8.

21. Kwiterovich PO, Coresh J, Smith HH, Bachorik PS, Derby CA, Pearson TA. Comparison of the plasma levels of apolipoproteins B and A-I and other risk factors in men and women with premature coronary artery disease. Am J Cardiol 1992;69:1015-21.

22. Wakatsuki A, Sagara Y. Lipoprotein metabolism in postmenopausal and oophorectomized women. Obstet Gynecol 1995;85:523-8.

23. Kuller LH, Meilahn EN, Cauley JA, Gutai JP, Matthews KA. Epidemiologic studies of menopause: Changes in risk factors and disease. Exp Gerontol 1994;29:495-509.

24. Kannel WB. Studies of coronary heart disease risk factors: Perspective from the Framingham study. Am Heart J 1987;114:413-9.

25. Swarnalatha PK, Ebrahim NK. A correlative study of estrogen and lipid profile in premenopausal and postmenopausal women. Int $\mathrm{J}$ Biomed $\mathrm{Adv}$ Res 2012;03:11.

26. Padubidri VG, Daftary SN. Howkins and Bourne Shaw's Textbook of Gynaecology. 13 th ed. New Delhi: Elsevier; 2004. p. 568.

27. Spencer CP, Godsland H, Stevenson JC. Is there a menopausal metabolic syndrome? Gynecol Endocrinol 1977;11:341-55. 
28. Adashi EY. The climacteric ovary as a functional gonadotropin driven androgenproducing gland. Fertil Steril 1994;62:207.

29. Barrett-Connor E, Bush TL. Estrogen and coronary heart disease in women. JAMA 1991;265:1861-7.

30. Groedstein F, Stampfer MJ, Manson JE, Colditz GA, Willet WC, Rosner B, et al. Post-menopausal estrogen and progestin use and the risk of cardiovascular disease. N Engl J Med 1996;335:453-61.

31. Wild RA, Taylor EL, Knehans A. The gynecologist and the prevention of cardiovascular disease. Am J Obstet Gynecol 1995;172:1-13.

32. Arora S, Jain A, Chitra R. Effects of shortterm hormone replacement on atherogenic indices in Indian postmenopausal women. Indian J Clin Biochem 2006;21:41-7

33. 33. Welty FK. Cardiovascular disease and dyslipidemia in women. Arch Intern Med 2001;161:514-22.

34. Tankó LB, Bagger YZ, Qin G, Alexandersen P, Larsen PJ, Christiansen C. Enlarged waist combined with elevated triglycerides is a strong predictor of accelerated atherogenesis and related cardiovascular mortality in postmenopausal women. Circulation 2005;111:1883-90.

35. Abbott RD, Wilson PW, Kannel WB, Castelli WP. High density lipoprotein cholesterol, total cholesterol screening, and myocardial infarction. The Framingham Study. Arteriosclerosis 1988;8:207-11.

36. Stampfer MJ, Colditz GA. Estrogen replacement therapy and coronary heart disease: A quantitative assessment of the epidemiologic evidence. Prev Med 1991;20:47-63.
37. Cheng GS. Cardiac events increased in the first 2 years of HRT. Intern Med News 2000;33:1-2. 